\title{
Estimation And Compensation of Angular Misalignment At Robot End Brush Roller - Workpiece Contact Interface Via Elastic Contact Force Perception
}

\author{
Xiaozhi Feng \\ Wuhan University of Technology \\ Rui LV \\ Wuhan University of Technology \\ Chen Qian \\ Wuhan University of Technology \\ Yudi Wang \\ Wuhan University of Technology \\ Linli Tian ( $\nabla$ tll@whut.edu.cn ) \\ Wuhan University of Technology \\ Dahu Zhu \\ Wuhan University of Technology
}

\section{Research Article}

Keywords: Robotic grinding, Brush roller tool, Force control, Angular misalignment estimation, Geometric error compensation

Posted Date: December 29th, 2021

DOI: https://doi.org/10.21203/rs.3.rs-1180415/v1

License: () (i) This work is licensed under a Creative Commons Attribution 4.0 International License. Read Full License 


\section{Abstract}

When the non-standard customized brush roller tool is used for robotic grinding of large-scale components, the clamping and positioning error of the brush roller at the end of the robot is extremely easy to cause misalignment at the brush roller - workpiece contact interface, which will affect the machining accuracy and surface quality. In order to ensure the parallel contact between the brush roller and the workpiece surface during the machining process, a calculation model of the angular misalignment at the brush roller - workpiece contact interface is proposed based on the elastic contact force perception, and then the accurate positioning of the robot end brush roller is realized by a fast compensation method. Firstly, according to the geometric force relationship between the brush roller and the workpiece, as well as the determined brush roller material properties parameters, the estimation model of angular misalignment is established. Secondly, both the axial force and normal torque at the time of initial contact detected by the force-controlled sensor are regarded as the input parameters in the model. Further, the calculated brush roller - workpiece contact offset is used as the geometric error compensation amount, and the brush roller is deflected to achieve error compensation by the robot RAPID program control command. The finite element simulation results are compared with the theoretical calculation values, and the average relative error is $15.1 \%$. The experiment on robotic grinding and brushing of high-speed rail body indicates that the compensated angle can be reduced to $0.024^{\circ}$ from an average of $0.179^{\circ}$ before compensation, coupled with uniform material removal depth. The proposed method can significantly improve the contour accuracy of large-scale components.

\section{Introduction}

Robotic grinding technology is an important means to improve the high-efficiency and high-quality machining in the fields of aerospace, rail transit and automobile [1]. At present, it is generally considered that the machining geometric error is the main problem to restrict the application of robotic grinding in the machining of large and complex components $[2,3]$. The error sources mainly include the pose error of the machining system, the kinematic error of the robot joints, and the positioning error under the end load of the robot, among which the pose error of the machining system is particularly prominent.

In order to reduce the pose error of the robotic machining system, extensive studies have been conducted from the perspectives of robot pose [4, 5], hand-eye pose [6, 7], workpiece pose [8, 9] and tool pose [8], and significant progresses have been made. When a robot is used as the equipment executive to perform grinding on the surface of large and complex components, the $A C F, A O K, A B G$ and other compliant flanges [10] are often used as the end effectors. In fact, another type of tool that uses brush roller installed at the robot end is used to improve the machining efficiency due to the larger contact area. The brush roller, however, is generally a nonstandard customized tool which will result in angular misalignment during manufacturing and installation, and then causes misalignment at the brush roller - workpiece contact interface. Consequently, uneven force on the workpiece surface coupled with alternating shades will be generated, and seriously, the misalignment may even cause scrapped parts by over-cutting.

Currently there are three main methods to compensate for the clamping and positioning error of tool at the end of robot: kinematic calibration methods [11-13], measurement and estimation of positional errors using laser trackers [14-17], and correction of clamping errors by force control [18-21]. Although the former two methods improve the positioning accuracy of the tool frame, the positioning error caused by the manufacturing and installation of the tool is not specifically compensated. Comparatively, the force control method is designed to compensate for positioning errors caused by the deformation of the tool spindle stiffness at the end of the robot, but it is not suitable for compensation of positioning errors in tools with large spindle stiffness and dimensions.

Based on this, a model for calculating the angular misalignment at the robot end brush roller - workpiece contact interface is proposed based on the elastic contact force perception. The model is verified based on ABAQUS analysis and grinding experiment, which effectively simplifies the complex calculation process encountered by the existing methods. By virtue of this method, the precise positioning of the robot end brush roller helps enhance the machining contour accuracy and surface quality of large and complex components.

\section{Problem Description}

When the robot is used for grinding the surface of large-scale components, it is a common way of perceiving and controlling contact forces by an external force-controlled sensor, so as to obtain the desired surface quality and contour accuracy [22, 23]. In the machining process, the ideal contact state between the brush roller and the workpiece is shown in Fig. 1(a). However, when the brush

Page 2/19 
roller behaves clamping and positioning errors, the angular misalignment at the brush roller - workpiece contact interface occurs as shown in Fig. 1(b). Moreover, slight elastic deformation is generated at the brush roller-workpiece contact interface under the action of force due to the flexible robotic machining system. In the subsequent force control machining, the under-cutting and over-cutting phenomena occurs owing to the unevenly stressed surface, which increases the unevenness and roughness of the workpiece surface, and makes the workpiece to be scrapped seriously.

\section{Calculation Model Of The Angular Misalignment At Brush Roller - Workpiece Contact Interface}

\subsection{Analysis of the elastic contact force between brush roller and workpiece}

When the brush roller at the end of the robot initially contacts with the workpiece surface, the contact interface will be elastically deformed due to squeezing, thereby resulting in certain deformation volume $\Delta V$. Both the deformation stress $\sigma$ and deformation volume $\Delta V$ follow Hooke's law. In the elastic properties of an object, the ratio of stress to volume change due to the action of hydrostatic pressure is named as compressive modulus, which is given by [24]:

$$
K_{i}=\frac{\sigma}{\Delta V_{i}}=\frac{E_{i}}{3\left(1-2 v_{i}\right)} \quad i=1,2
$$

1 where $K_{1}$ and $K_{2}$ are the bulk modulus of brush roller and workpiece, $\Delta V_{1}$ and $\Delta V_{2}$ are the elastic deformation volume of brush roller and workpiece, $E_{1}$ and $E_{2}$ are the elastic modulus of brush roller and workpiece, and $v_{1}$ and $v_{2}$ are the Poisson's ratio of brush roller and workpiece.

As illustrated in Fig. 2, the contact force between the brush roller and the workpiece is an interaction force, thus the deformation stress acting on the brush roller and the workpiece is equal, it has:

$$
K_{1} \Delta V_{1}=K_{2} \Delta V_{2}=\sigma
$$

2

To simplify the calculation, it is assumed that the sum of the elastic deformation volume of the brush roller and workpiece is $\Delta V=\Delta V_{1}+\Delta V_{2}$. Substituting it into Eq. (2), it yields:

$$
\frac{K_{1} K_{2}}{K_{1}+K_{2}} \Delta V=\sigma
$$

3

Therefore, the elastic deformation contact force by the brush roller can be expressed as:

$$
F=\sigma A=\frac{K_{1} K_{2}}{K_{1}+K_{2}} \Delta V A
$$

\section{4}

In the elastic contact deformation, when the stiffness of the brush roller is much smaller than that of the workpiece, the elastic contact area $A$ can be approximated to a semi-ellipse, as shown in the shaded part in Fig. 2(a), then it has:

$$
A=\Pi a b / 2
$$

$$
\left\{\begin{array}{c}
a=L / \cos \alpha \\
b=\sqrt{R^{2}-(R-L \cdot \tan \alpha)^{2}}
\end{array}\right.
$$


where $a$ and $b$ are the long and short semi-axes of the semi-ellipse in the contact area, $L$ is the length of the brush roller busbar in the elastic deformer, $R$ is the brush roller radius and $a$ is the deflection angle between the brush roller and the workpiece surface.

In the robot end tool coordinate system as shown in Fig. 2(a), the origin is located at the midpoint of the generatrix of the brush roller, and $\mathrm{X}, \mathrm{Y}$ and $\mathrm{Z}$ represent the tangential, axial and normal directions. For the elastic deformation between the actual brush roller and the workpiece, $\Delta x_{\text {max }}$ is the maximum amount of deformation in a certain section in the elastic deformation volume, $\beta_{\text {imax }}$ is the angle between the critical deformation point and the maximum deformation point in a certain section of the elastic deformation volume. A mathematical method is used to integrate the cross-sectional area in Fig. 2(b) from the axial direction of the brush roller, which aims to calculate the elastic deformation volume:

$$
\Delta V=\int_{0}^{L} \beta_{\text {imax }} R^{2}-\left(R-\Delta x_{\text {imax }}\right)^{2} \tan \beta_{\text {imax }} d L
$$

7

Combining Eqs. (4) to (7), the elastic contact force $F$ by the brush roller can be expressed as:

$$
F=\frac{K_{1} K_{2} \Pi а b}{2\left(K_{1}+K_{2}\right)} \int_{0}^{L}\left[\beta_{\text {imax }} R^{2}-\left(R-\Delta x_{\text {max }}\right)^{2} \tan \beta_{\text {max }}\right] d L
$$

8

Furthermore, it can be seen from the geometric relationship in Fig. 2:

$$
\beta_{\text {imax }}=\left|\cos ^{-1} \frac{R-\Delta x_{\text {imax }}}{R}\right|
$$

9

$$
\Delta x_{\text {imax }}=L_{i} \tan \alpha
$$

10

where $L_{i}$ is the micro-element length of the generatrix length $L$ of the brush roller in the elastic deformation body.

\subsection{Determination of the material properties parameters of brush roller material}

The brush roller is composed of an aluminum alloy core, an external non-woven fabric, and silicon carbide abrasive grains on the surface of the non-woven fabric. In order to improve the calculation accuracy, the actual model of the brush roller is simplified according to the following classic calculation formula of Young's modulus [25] to obtain the combined elastic modulus of the brush roller.

$$
E=(F / S) /(d L / r)
$$

11

As shown in Fig. 3, when the brush roller is subjected to positive pressure $F$, the amount of deformation is the sum of the elastic deformation produced by both the aluminum alloy core and the non-woven fabric.

$$
E_{1}^{\prime}=\left(F \mid \frac{r_{1}}{r_{2}} S\right) /\left(d_{L 1} / r_{1}\right)
$$




$$
E_{2}^{\prime}=(F / S) /\left(d_{L 2} /\left(r_{2}-r_{1}\right)\right)
$$

13

where $E_{1}$ is the elastic modulus of the aluminum alloy core, which is taken as $70 \mathrm{GPa}, E_{2}$ is the elastic modulus of polypropylene, the raw material of non-woven fabrics, which is taken as $1.35 \mathrm{GPa}$. Assuming that under positive pressure, the contact area between the brush roller and the workpiece is $S$, the area where the pressure acts on the surface of the aluminum alloy core is $r_{1} S / r_{2}$. The amount of deformation of the aluminum alloy core under the positive pressure is $d_{L 1}$, the amount of deformation of non-woven fabric is $d_{L 2}, r_{1}$ is the radius of the aluminum alloy core, which is $37.5 \mathrm{~mm}$, and $r_{2}$ is the radius of the brush roller, which is $75 \mathrm{~mm}$.

Both Eqs. (12) and (13) are used to express the amount of elastic deformation of the aluminum alloy core and the non-woven fabric, respectively, which are given by:

$$
d_{L 1}=\frac{F r_{2}}{S E_{1}^{\prime}}
$$

14

$$
d_{L 2}=\frac{F\left(r_{2}-r_{1}\right)}{S E_{2}^{\prime}}
$$

15

Then the total amount of elastic deformation of the brush roller can be expressed as:

$$
d_{L}=d_{L 1}+d_{L 2}
$$

16

Furthermore, the combined elastic modulus of the brush roller is rewritten as:

$$
E=\frac{E_{1}^{\prime} E_{2}^{\prime} r_{2}}{E_{2}^{\prime} r_{2}+E_{1}^{\prime}\left(r_{2}-r_{1}\right)}
$$

17

Finally, the elastic modulus of the brush roller is determined as $E=2.559 \mathrm{GPa}$, namely the value of $E_{1}$ in Eq. (1) is $2.559 \mathrm{GPa}$.

Poisson's ratio refers to the ratio of the absolute value of the transverse normal strain to the axial normal strain when the material is under tension or compression in one direction. Thus the combined Poisson's ratio of the brush roller is calculated as:

$$
\nu=\frac{r_{1}}{r_{2}} \nu_{1}+\frac{r_{2}-r_{1}}{r_{2}} \nu_{2}
$$

18

where $\nu_{1}$ is the Poisson's ratio of the aluminum alloy core, which is $0.3, \nu_{2}$ is the Poisson's ratio of the polypropylene, which is 0.42 . The combined Poisson's ratio of the brush roller is calculated to be 0.36 , namely the value of $\nu_{1}$ in Eq. (1) is 0.36 .

\subsection{Estimation and compensation of the angular misalignment at contact interface}

During the robotic grinding process, the contact force on the brush roller is the resultant force of the normal, axial and tangential forces measured by the force sensor. When estimating the angular misalignment at the brush roller-workpiece contact interface, the tangential force is perpendicular to the contact force that causes the elastic deformation, thus it is not involved in the calculation 
and can be ignored. Therefore, the elastic contact force $F$ is considered as the vector sum of the normal force $\vec{F}_{n}$ and the axial force $\rightarrow$

$F_{a}$ measured by the force sensor.

$$
\vec{F}=\vec{F}_{n}+\vec{F}_{a}
$$

19

According to the axial force $F_{a}$ on the brush roller detected by the force sensor, both the contact force $F$ and the normal contact force $F_{n}$ caused by the angular misalignment of the brush roller can be calculated by trigonometric functions:

$$
F_{n}=F_{a} / \tan \alpha
$$

20

$$
F=F_{a} / \sin \alpha
$$

21

Due to the uneven distribution of the normal force acting on the contact surface, the resultant force is not at the midpoint of the brush roller generatrix, thus a torque $T_{n}$ around the $\mathrm{X}$ axis will be generated, as shown in Fig. 4 . The relationship between the torque $T_{\mathrm{n}}$ and the distance $L$ ' from the force action point to the bottom end of the brush roller is given by:

$T_{\mathrm{n}}=F_{\mathrm{n}} \times\left(\frac{D}{2}-L^{\prime}\right)$

where $D$ is the length of the brush roller generatrix.

Due to the linear relationship between the brush roller and the workpiece in elastic contact, the cross-sectional shape of the elastic deformation body is a right-angled triangle distribution as shown in Fig. 4. Taking the right-angle side at the resultant normal force's action point as the boundary, the areas of the two parts $S_{1}$ and $S_{2}$ of the right-angle triangle are equal. There is the following relationship between the contact length $L$ of the brush roller-workpiece and the distance $L^{\prime}$ from the action point of the resultant normal force to the bottom end of brush roller.

$L^{\prime}=\frac{2-\sqrt{2}}{2} L$

The brush roller-workpiece contact length $L$ can be expressed as:

$$
L=\frac{D-\frac{2\left|T_{\mathrm{n}}\right|}{\left|F_{\mathrm{a}}\right| / \tan \alpha}}{2-\sqrt{2}}
$$

24

Combining Eqs. (8), (9), (10), (20), (21) and (24), the calculation model of the angular misalignment at the brush roller-workpiece contact interface is given by Eq. (25). 


$$
\begin{aligned}
& \int^{0\left(D-\frac{2\left|T_{n}\right|}{\left|F_{a}\right| / \tan \alpha}\right)} 2 R\left|\cos ^{-1} \frac{R-L_{i} \cdot \tan \alpha}{R}\right| *\left[R^{2}\left|\cos ^{-1} \frac{R-L_{i} \cdot \tan \alpha}{R}\right|-\left(R-L_{i} \cdot \tan \alpha\right)^{2} \tan \left(\cos ^{-1} \frac{R-L_{i} \cdot \tan \alpha}{R}\right)\right] d L_{i} \\
& =\frac{2\left(K_{1}+K_{2}\right) \cos \alpha}{\overline{\left(F_{a} / \sin \alpha\right)^{2}+F_{a}^{2}}} \\
& \left.K_{1} K_{2} \frac{\left(D-\frac{2\left|T_{\mathrm{n}}\right|}{\left|F_{\mathrm{a}}\right| / \tan \alpha}\right)}{2-\sqrt{2}} \sqrt{R^{2}-} R-\frac{\left(D-\frac{2\left|T_{\mathrm{n}}\right|}{\left|F_{a}\right| / \tan \alpha}\right)}{2-\sqrt{2}}\right)^{2}
\end{aligned}
$$

25

where both $F_{a}$ and $T_{n}$ can be directly measured by the six-dimensional force sensor, only the deflection angle $a$ is unknown. Taking $F_{a}$ and $T_{n}$ as the input and the deflection angle $a$ as the output, the relationship between input and output of the model under different contact lengths $L$ is shown in Fig. 5.

To compensate for the angular misalignment at the brush roller-workpiece contact interface, the rotation direction of $a$ is determined by the direction of the axial force $\vec{F}_{a}$, as shown in Fig. 6 . If $\vec{F}_{a}$ is less than zero, rotate the robot end tool coordinate system clockwise around the $\mathrm{X}$ axis by an angle $a$ to compensate for the angular misalignment at the brush roller-workpiece contact interface. Otherwise, rotate it counterclockwise.

\section{Simulation Verification}

The commercial CAE software ABAQUS is used to simulate and verify the above contact force model. The finite element simulation model corresponding to the theoretical model is shown in Fig. 7. Note that the positioning contact between the brush roll and the workpiece is used. The workpiece material is 6005A-T6 aluminum alloy, with the dimension of $300 \mathrm{~mm} \times 100 \mathrm{~mm} \times 2 \mathrm{~mm}$, and the generatrix height of the brush roller is $240 \mathrm{~mm}$.

Owing to the high mesh accuracy required for the micro-contact simulation calculation, only the yellow part in Fig. 7(a) is calculated during the simulation to enhance the simulation speed and efficiency, as shown in Fig. 7(b). The material properties parameters of the brush roller and workpiece are listed in Table 1. A completely fixed operation is adopted on the non-working surface of the brush roller and the workpiece to simulate the actual situation. Also the deflection angle is artificially set to make a small elastic contact between the brush roll and the workpiece. The simulation results are the contact pressure and torque on the contact surface.

Table 1

Material properties parameters of the brush roller and workpiece.

\begin{tabular}{|lll|}
\hline Parameter & Brush roller & Workpiece \\
\hline$E$ & $2.559 \mathrm{GPa}$ & $70 \mathrm{GPa}$ \\
\hline$U$ & 0.36 & 0.3 \\
\hline
\end{tabular}

The simulation takes the generatrix center on the surface of the brush roller as the rotation center, and misalignment angles of $0.1^{\circ}$, $0.2^{\circ}, 0.3^{\circ}, 0.4^{\circ}$, and $0.5^{\circ}$ are set for analysis. Both the axial contact pressure CFN3 and the torque around the $\mathrm{X}$ axis in the output of the simulation result history are used as the input of the theoretical model, then the misalignment angle corresponding to the elastic deformation is calculated for model inverse verification. Five sets of simulation results are shown in Fig. 8 and Fig. 9, respectively. Table 2 compares the simulation results and the output data of the theoretical model.

It can be seen from the contact stress CPRESS cloud in Fig. 8 that the cross-sectional distribution of the contact force is an isosceles triangle with the $\mathrm{Y}$-axis as the midline. This result is consistent with the calculation of the contact force in the theoretical model described above. Furthermore, the symbol cloud diagram of the reaction force RT in Fig. 9 shows that the longitudinal cross-

Page $7 / 19$ 
sectional distribution of the contact reaction force is a right triangle. This result is consistent with the calculation of the contact force in the above theoretical model. These results validate the correctness of the elastic contact force analysis between the brush roll and the workpiece.

Table 2 indicates that the misalignment angle required for the simulation is smaller compared to the angular misalignment output from the theoretical model under the same conditions. This is mainly because the contact area simplified as the surface area of the deformed part of the brush roller is smaller than the actual contact area in the theoretical modelling process. The stiffness of the brush roller is much smaller than that of the workpiece, hence the results by the theoretical model and the finite element simulation calculation are not the same. The average relative error between the simulated and theoretical values is $15.1 \%$, which is within an acceptable range.

Table 2

Comparison of the simulation and theoretical results.

\begin{tabular}{|lllll|}
\hline $\begin{array}{l}\text { Simulation } \\
\text { misalignment } /{ }^{\circ}\end{array}$ & $\begin{array}{l}\text { Axial force during contact } \\
\text { simulation /N }\end{array}$ & $\begin{array}{l}\text { Torque around X-axis during } \\
\text { contact simulation /N·m }\end{array}$ & $\begin{array}{l}\text { Output misalignment of } \\
\text { theoretical model / }\end{array}$ & $\begin{array}{l}\text { Relative } \\
\text { error }\end{array}$ \\
\hline 0.1 & 0.00105 & 0.0406 & 0.137 & $27.0 \%$ \\
\hline 0.2 & 0.00572 & 0.1237 & 0.242 & $17.4 \%$ \\
\hline 0.3 & 0.01459 & 0.2352 & 0.330 & $9.1 \%$ \\
\hline 0.4 & 0.03588 & 0.4069 & 0.462 & $13.4 \%$ \\
\hline 0.5 & 0.06591 & 0.6017 & 0.548 & $8.8 \%$ \\
\hline
\end{tabular}

\section{Experimental Verification And Result Discussion}

The experimental platform of robotic grinding and brushing of high-speed rail body is built, as shown in Fig. 10, which mainly includes a six-degree-of-freedom ABB industrial robot (IRB 6700-200/2.6) with an end load capacity of $200 \mathrm{Kg}$ and repeated positioning accuracy $0.05 \mathrm{~mm}$. An F/T sensor (ATI Omega 160) is installed at the end of the sixth axis of the robot to measure contact force and torque. The tool is a non-standard customized brush roller with a diameter of $150 \mathrm{~mm}$ and a height of $240 \mathrm{~mm}$, which is mainly made of aluminum alloy as the core material, and the outer layer is a non-woven fabric with silicon carbide abrasive.

Before the experiment, the tool coordinate system is calibrated by the "four-point method" that comes with the robot operating system, and the "three-point method" is used to complete the calibration of the workpiece coordinate system [8]. After calibration, two vertical machining paths are planned under the constant force control mode with a normal force of $5 \mathrm{~N}$ to ensure the contact between brush roller and workpiece and to avoid the damage of the brush roller to the workpiece. When the brush roller does not rotate, the robot completes the first path movement. As shown in Fig. 11, the contact forces and torques on the brush roller are detected by the ATI force control sensor during robot operation. According to the model input requirement, the data in the middle 1/2 representing the axial force and the torque around the $\mathrm{X}$ axis are extracted, then the average values are calculated as $F_{a}=-0.0162 \mathrm{~N}$ and $T_{n}=0.2900 \mathrm{~N} \cdot \mathrm{m}$. These values are input into the calculation model of angular misalignment at brush roller-workpiece contact interface, the compensated angle is finally calculated as $0.232^{\circ}$.

Before the robot performs the second machining path, the brush roller is rotated clockwise around the $\mathrm{X}$ axis to compensate the misalignment angle of $0.232^{\circ}$ through the robot controller RAPID program control instruction. During the machining process, the optimal parameters combination determined by large amount of process tests [26] is selected: the brush roller speed of $11.8 \mathrm{~m} / \mathrm{s}$, the workpiece feed speed of $10 \mathrm{~mm} / \mathrm{s}$, and the normal force of $20 \mathrm{~N}$. Finally, thirty times of grinding and brushing operations are performed to facilitate the measurement of experimental results.

When the machining operation is completed, the machined surface of the high-speed rail body is scanned by a PowerScan-Pro-2.3M scanner (measuring accuracy $\pm 0.02 \mathrm{~mm}$ ) to obtain spatial point cloud data, so as to quantitatively analyze the depth of material removal after grinding and brushing. Due to the limitations of the scanner single-frame photo range and the quality of the entire point cloud, the scanned results are selected separately within the Imageware software for one $160 \mathrm{~mm} \times 60 \mathrm{~mm}$ equally spaced measurement range on each machining path, as shown in Fig. 12. The measurement results are represented as a chromatogram, 
where the horizontal coordinate indicates the horizontal direction of the machining area, the vertical coordinate indicates its vertical direction, and the color indicates the material removal depth. The point cloud data at three horizontal positions on each path are selected for further analysis, and the relevant data are shown in Figs. 13 and 14.

Figure 13 shows that the material removal depth in the machined area without angular misalignment compensation is not uniform, and the color gradient varies significantly. The problem of excessive removal at one end and insufficient removal depth at the other also exists. Specifically, the pre-machining reference of the rail body shown in Position 1, Position 2, and Position 3 constitutes an obvious angle with the spatial point cloud data after machining, respectively. After data processing and calculation, the three included angles are $0.167^{\circ}, 0.179^{\circ}, 0.192^{\circ}$, and the average value is $0.179^{\circ}$.

In contrast, Fig. 14 shows that the color distribution of the machining areas after angular misalignment compensation is more uniform, and the included angles at Position 1, Position 2, and Position 3 are $-0.034^{\circ},-0.021^{\circ}$, and $-0.018^{\circ}$, respectively. The average value is only $-0.024^{\circ}$, indicating that the depth of material removal is relatively uniform, and the contour accuracy after grinding and brushing has been improved significantly.

\section{Conclusion}

The angular misalignment caused by the clamping and positioning errors of the non-standard customized brush roller is a challenging task facing the robotic grinding of large-scale components. In this paper, a calculation model of the angular misalignment at the brush roller - workpiece contact interface is proposed to address the problem based on the elastic contact force perception. The following conclusions are achieved:

(1) Calculation of the misalignment angle at the robot end brush roller - workpiece contact interface needs to comprehensively consider the geometrical force relationship between the brush roller and the workpiece at the initial contact, and to determine the combined elastic modulus and Poisson's ratio of the brush roller.

(2) When the angular misalignment is determined by taking the axial force and normal torque as input parameters of the model, rotating the corresponding angle of the brush roll by means of a robot controller RAPID program command can rapidly compensate for the clamping and positioning error of the brush roller.

(3) By comparing the simulation and theoretical values, the minimum error under the condition of brush roller-workpiece misalignment angle of $0.1^{\circ} \sim 0.5^{\circ}$ is only $0.03^{\circ}$, and the average relative error is $15.1 \%$. The compensated angle is reduced to $0.024^{\circ}$ from the average of $0.179^{\circ}$ before compensation, and the depth of material removal becomes more uniform.

\section{Declarations}

\section{Funding information}

This study is financially supported by the National Nature Science Foundation of China (No. 51975443), the Hubei Province Key R\&D Program (No. 2020BAA025).

\section{Declaration of competing interest}

The authors declare that they have no known competing financial interests or personal relationships that could have appeared to influence the work reported in this paper.

\section{Data availability statement}

The data and materials of this manuscript are available from the corresponding author on reasonable request.

\section{Code availability}

Not applicable.

\section{Ethics approval}


The authors claim that none of the contents in this manuscript has been published or considered for publication elsewhere. Besides, the research contents of the article do not violate ethics.

\section{Consent to participate}

The research does not involve human participants or animals, and the authors warrant that the manuscript fulfills the ethical standards of the journal.

\section{Consent for publication}

All authors give consent to publish this manuscript in the International Journal of Advanced Manufacturing Technology.

\section{Author contribution}

Xiaozhi Feng: Conceptualization, investigation, writing - original draft, writing - review \& editing,methodology. Rui Lv: Methodology, validation, writing. Chen Qian: Methodology, writing - reviewing and editing. Yudi: Wang: Investigation, writing - reviewing and editing. Linli Tian: Methodology, writing - reviewing and editing. Dahu Zhu: Funding acquisition, writing - reviewing and editing.

\section{References}

1. Zhu D, Feng X, Xu X, Yang Z, Li W, Yan S, Ding H (2020) Robotic grinding of complex components: A step towards efficient and intelligent machining - challenges, solutions, and applications. Robot Cim-Int Manuf 65:101908

2. Li W, Xie H, Yin Z, Ding H (2021) The research of geometric error modeling of robotic machining: I spatial motion chain and error transmission. J Mech Eng 57(7):154-168

3. Li W, Xie H, Yin Z, Ding H (2021) The research of geometric error modeling of robotic machining: Il parameter identification and pose optimization. J Mech Eng 57(7):169-184

4. Jiang Z, Huang M, Tang X, Guo Y (2021) A new calibration method for joint-dependent geometric errors of industrial robot based on multiple identification spaces. Robot Cim-Int Manuf 71(1):102175

5. Luo G, Zou L, Wang Z, Lv C, Huang Y (2021) A novel kinematic parameters calibration method for industrial robot based on Levenberg-Marquardt and Differential Evolution hybrid algorithm. Robot Cim-Int Manuf 71(1):102165

6. Li W, Xie H, Zhang G, Yan S, Yin Z (2015) Hand-eye calibration in visually-guided robot grinding. IEEE Trans Cybern 46(11):2634-2642

7. Li M, Du Z, Ma X, Dong W, Gao Y (A robot hand-eye calibration method of line laser sensor based on 3D reconstruction. Robot Cim-Int Manuf 2021) ; 71(2017):102136

8. Xu X, Zhu D, Wang J, Yan S, Han D (2018) Calibration and accuracy analysis of robotic belt grinding system using the ruby probe and criteria sphere. Robot Cim-Int Manuf 51:189-201

9. Sun Y, Giblin D, Kazerounian K (2009) Accurate robotic belt grinding of workpieces with complex geometries using relative calibration techniques. Robot Cim-Int Manuf 25(1):204-210

10. Zhu D, Xu X, Jiang C, Li W (2021) Research progress in robotic grinding technology for complex blades. Acta Aeronautica et Astronautica Sinica 42(10):524265

11. Ren Y, Yin S, Zhu J (2012) Calibration technology in application of robot-laser scanning system. Opt Eng 51(11):114204

12. Ma L, Bazzoli P, Sammons P, Landers R, Bristow D (2018) Modeling and calibration of high-order joint-dependent kinematic errors for industrial robot. Robot Cim-Int Manuf 50:153-167

13. Luo X, Xie F, Liu X, Xie Z (2021) Kinematic calibration of a 5-axis parallel machining robot based on dimensionless error mapping matrix. Robot Cim-Int Manuf 70:102115

14. Nubiola A, Bonev I (2013) Absolute calibration of an ABB IRB 1600 robot using a laser tracker. Robot Cim-Int Manuf 29(1):236245

15. Zhao D, Dong C, Guo H, Tian W (Kinematic calibration based on the multicollinearity diagnosis of a 6-DOF polishing hybrid robot using a laser tracker. Math Probl Eng 2018) ; 2018:5602397 
16. Huang T, Zhao D, Yin F, Tian W, Chetwynd D (2019) Kinematic calibration of a 6-DOF hybrid robot by considering multicollinearity in the identification Jacobian. Mech Mach Theory 131:371-384

17. Boby R, Klimchik A (2021) Combination of geometric and parametric approaches for kinematic identification of an industrial robo. Robot Cim-Int Manuf 71:102142

18. Cen L, Melkote S, Castle J, Appelman H (2016) A wireless force-sensing and model-based approach for enhancement of machining accuracy in robotic milling. IEEE-ASME T Mech 21(5):2227-2235

19. Latifinavid M, Konukseven E (2017) Hybrid model based on energy and experimental methods for parallel hexapod-robotic light abrasive grinding operations. Int J Adv Manuf Technol 93(9-12):3873-3887

20. Latifinavid M, Donder A, Konukseven E (2018) High-performance parallel hexapod-robotic light abrasive grinding using real-time tool deflection compensation and constant resultant force control. Int J Adv Manuf Technol 96(9-12):3403-3416

21. Ye C, Yang J, Zhao H, Ding H (2021) Task-dependent workpiece placement optimization for minimizing contour errors induced by the low posture-dependent stiffness of robotic milling. Int J Mech Sci 205:106601

22. Wang Q, Wang W, Zheng L, Yun C (2021) Force control-based vibration suppression in robotic grinding of large thin-wall shells. Robot Cim-Int Manuf 67:102031

23. Xu X, Chen W, Zhu D, Ding H (2021) Hybrid active/passive force control strategy for grinding marks suppression and profile accuracy enhancement in robotic belt grinding of turbine blade. Robot Cim-Int Manuf 67:102047

24. Popov V (2010) Contact Mechanics and Friction: Physical Principles and Applications. Springer-Verlag, Berlin Heidelberg

25. Qu C, Lv Y, Yang Z, Xu X, Zhu D, Yan S (2019) An improved chip-thickness model for surface roughness prediction in robotic belt grinding considering the elastic state at contact wheel-workpiece interface. Int J Adv Manuf Technol 104(5):3209-3217

26. Zhu D, Wen Z, Xi W, Zhang M (2020) Parametric evaluation method for surface texture of high-speed railway body in white drawing. Journal of Huazhong University of Science and Technology (Natural Science Edition) 48(11):48-53

\section{Figures}

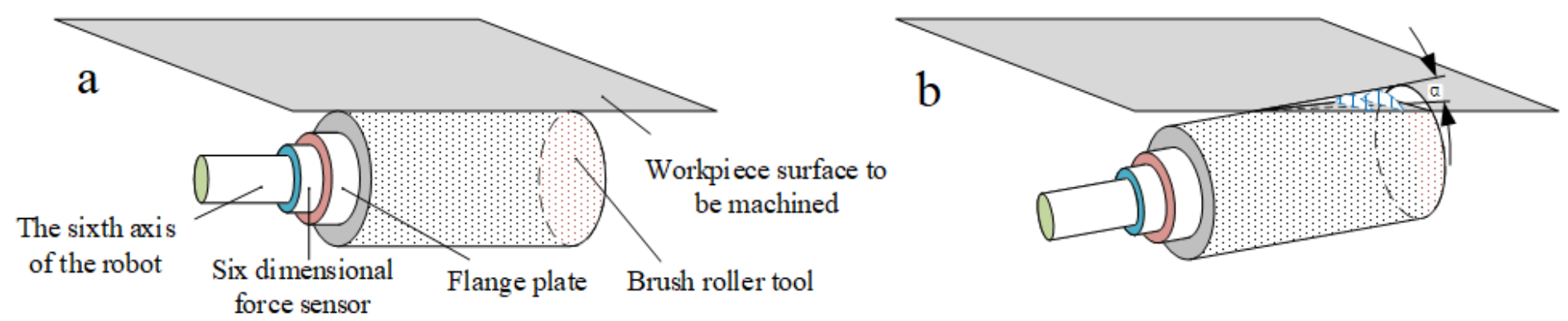

\section{Figure 1}

Schematic diagram of the (a) expected and (b) actual robot end brush roller-workpiece contact state during robotic grinding process. 

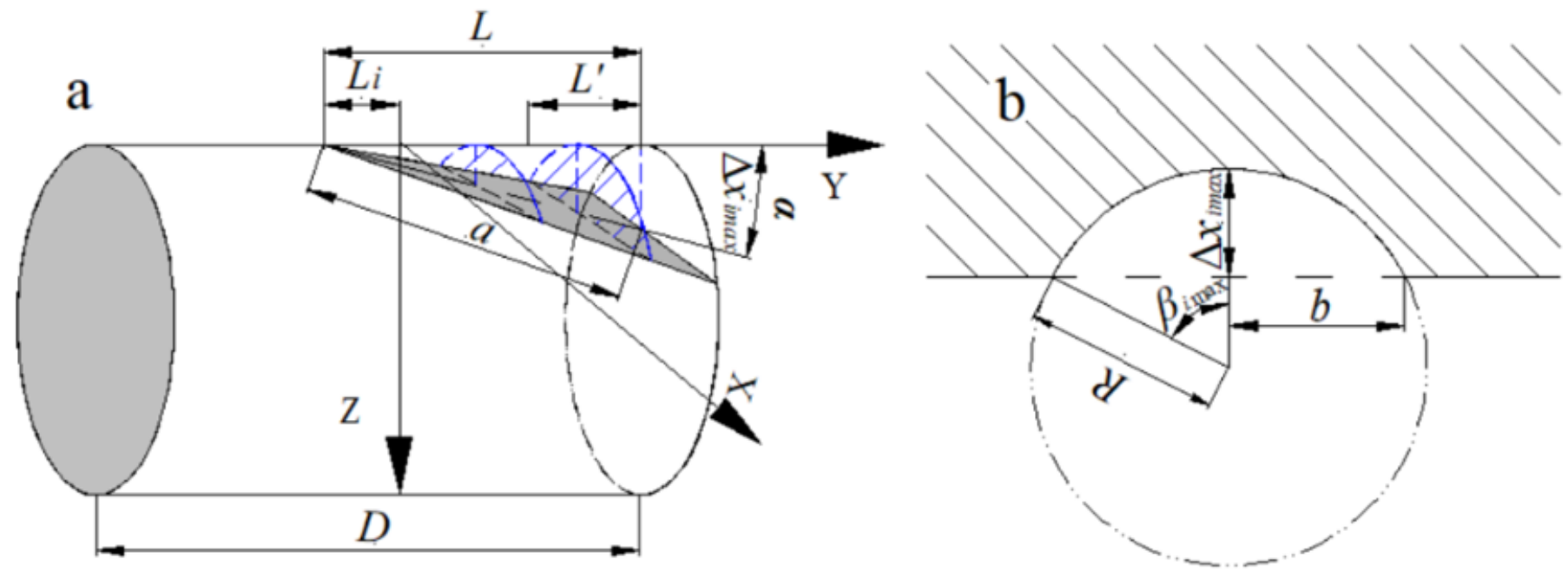

Figure 2

The geometric relationship diagram of the elastic deformation at the brush roller-workpiece contact interface from (a) main view and (b) left view.

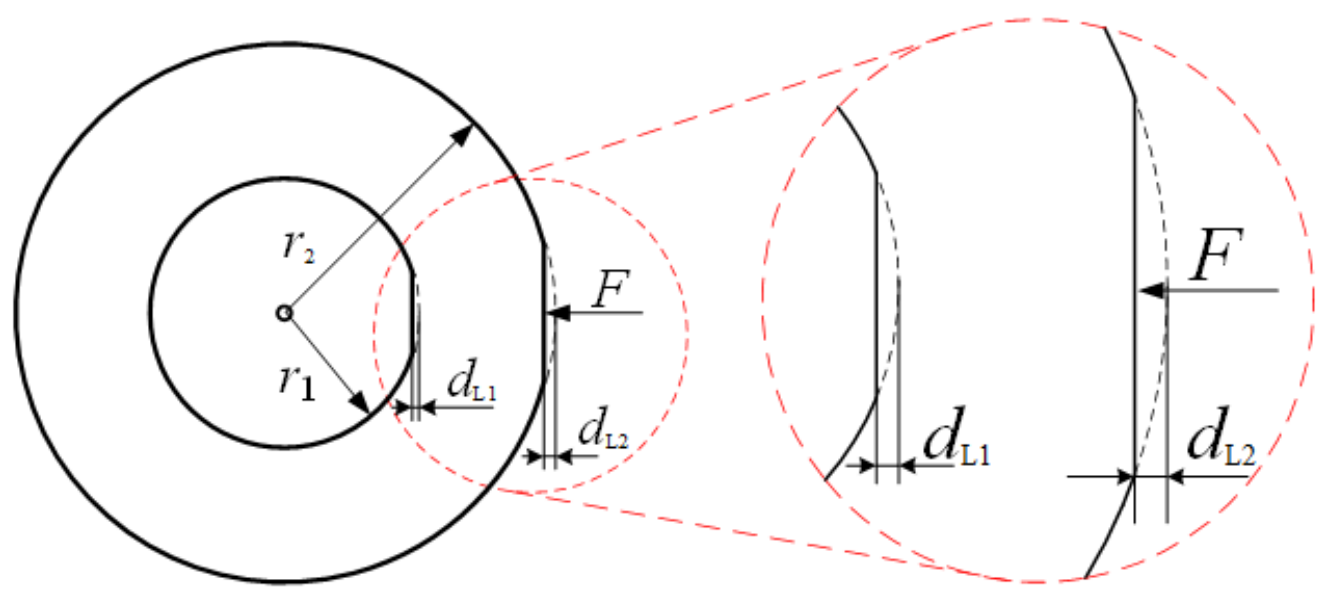

Figure 3

Schematic diagram of the elastic deformation of brush roller under positive pressure. 


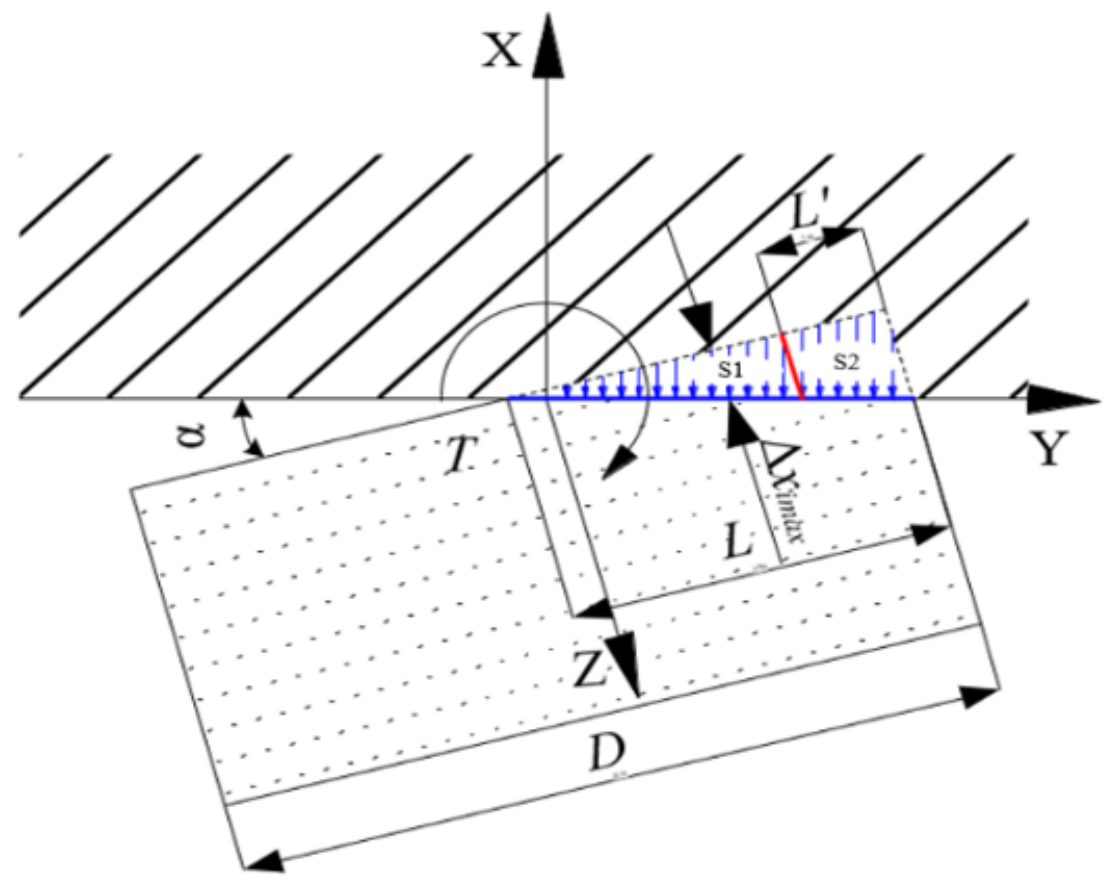

Figure 4

Schematic diagram of the distribution of contact force.

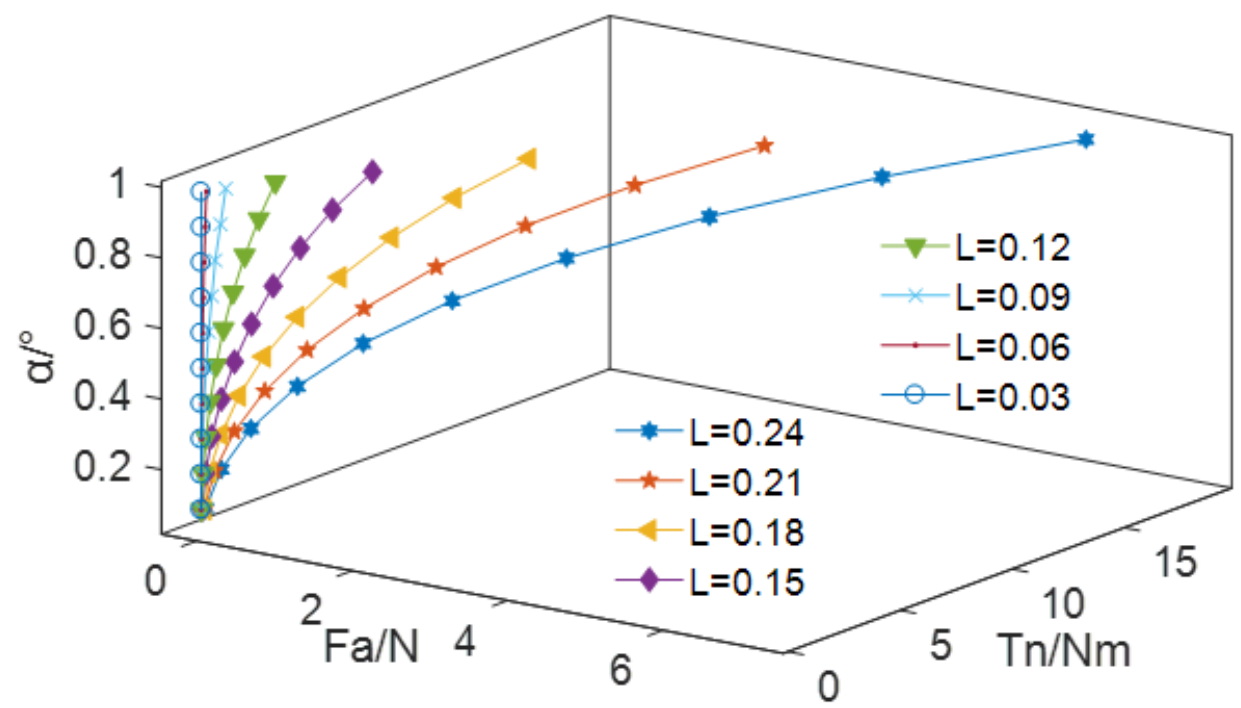

Figure 5

Relationship between input and output of the model under different contact lengths. 

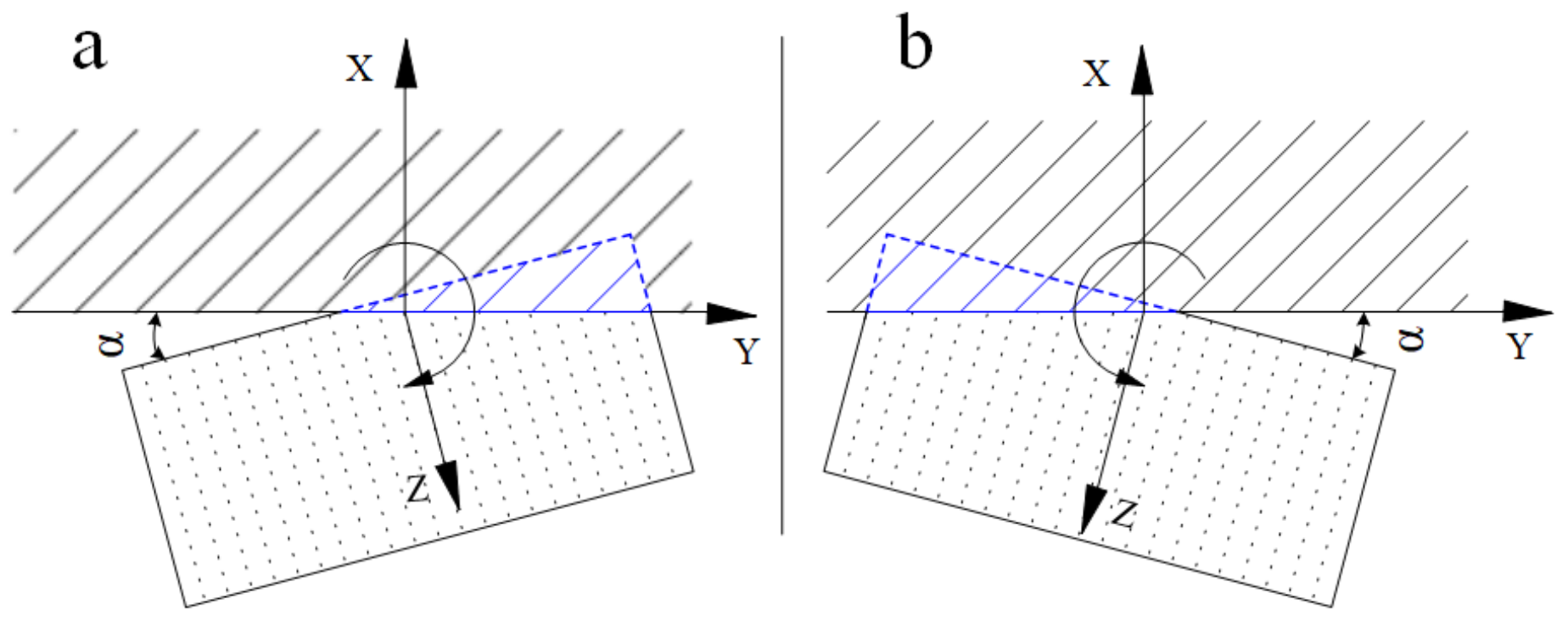

Figure 6

Compensation direction of misalignment angle at brush roller-workpiece contact interface from (a) clockwise and (b) counterclockwise.
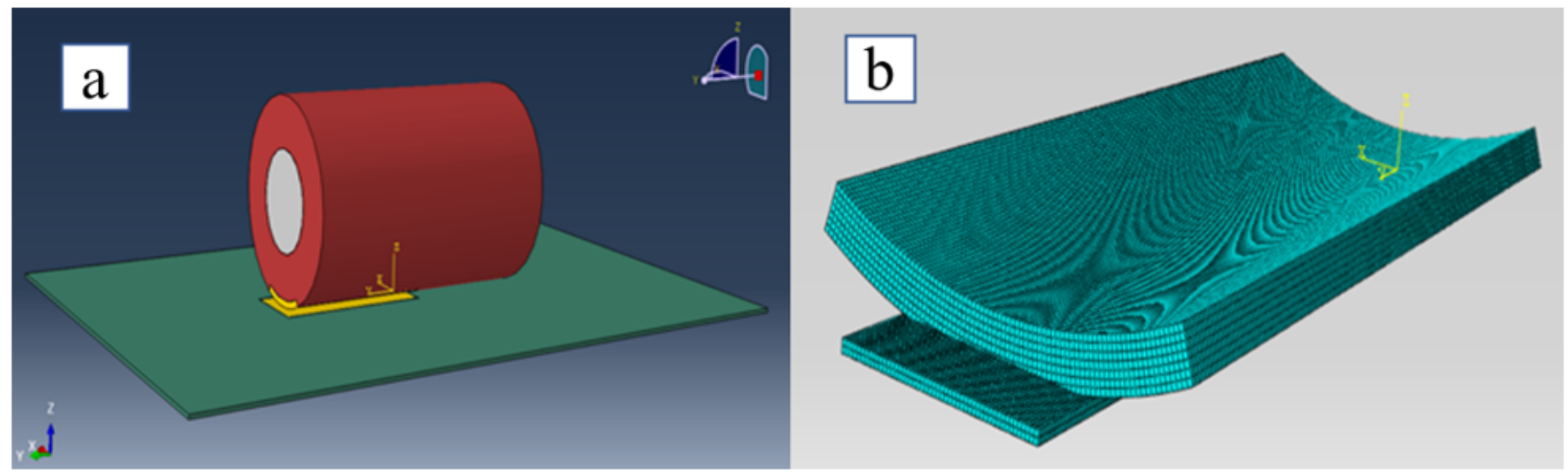

Figure 7

(a) Finite element simulation model and (b) simplified calculation model.

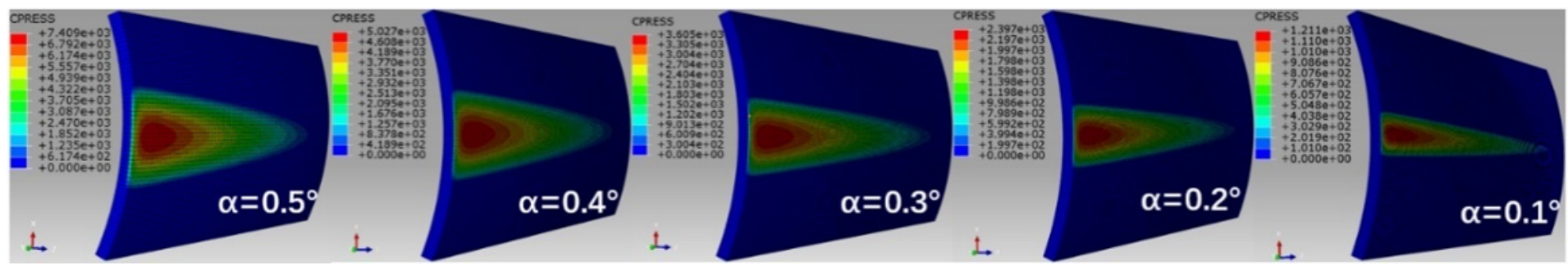

Figure 8

Contact stress cloud diagram with different deflection angles. 


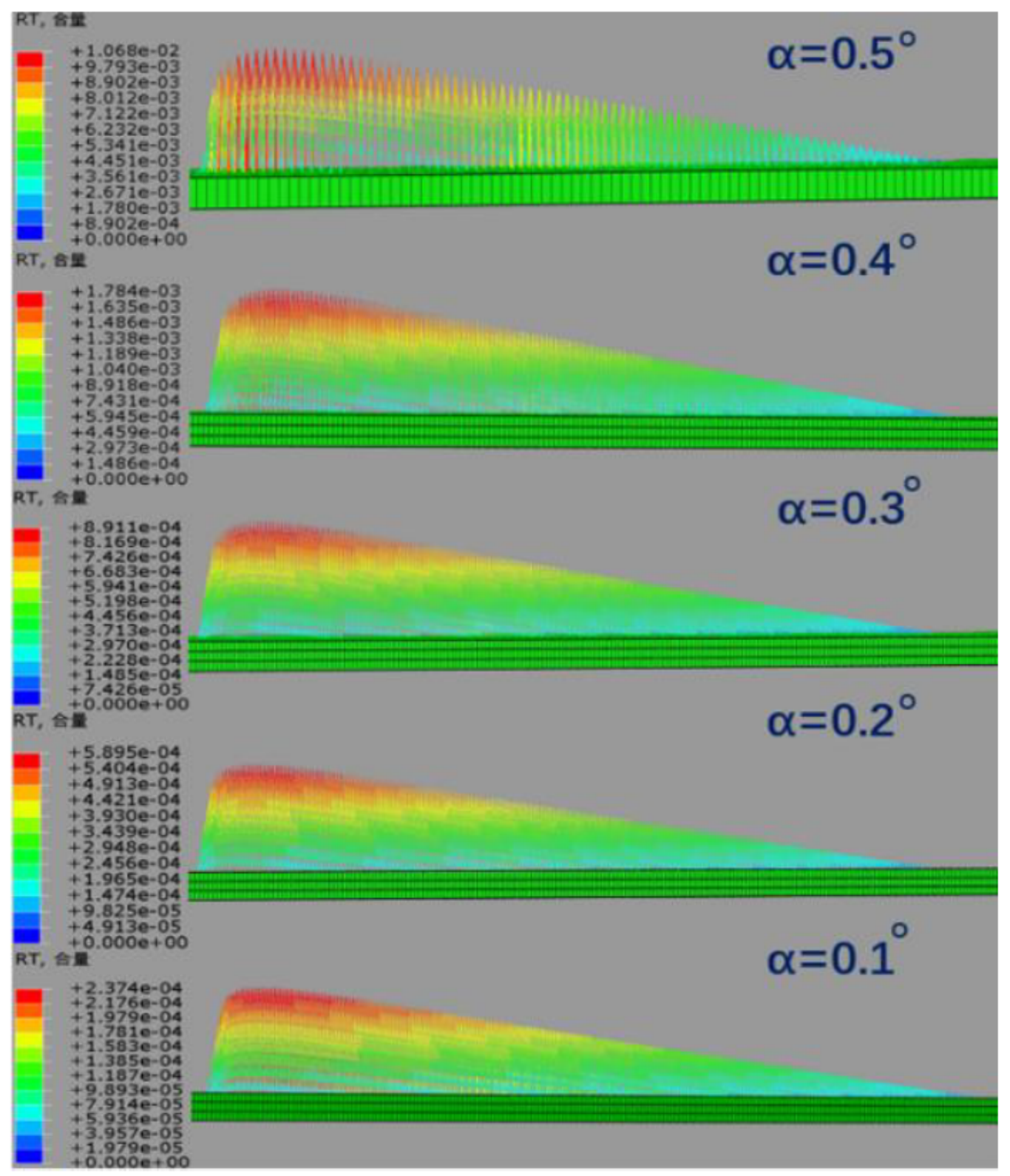

\section{Figure 9}

Symbol diagram of the contact reaction force with different misalignment angles. 


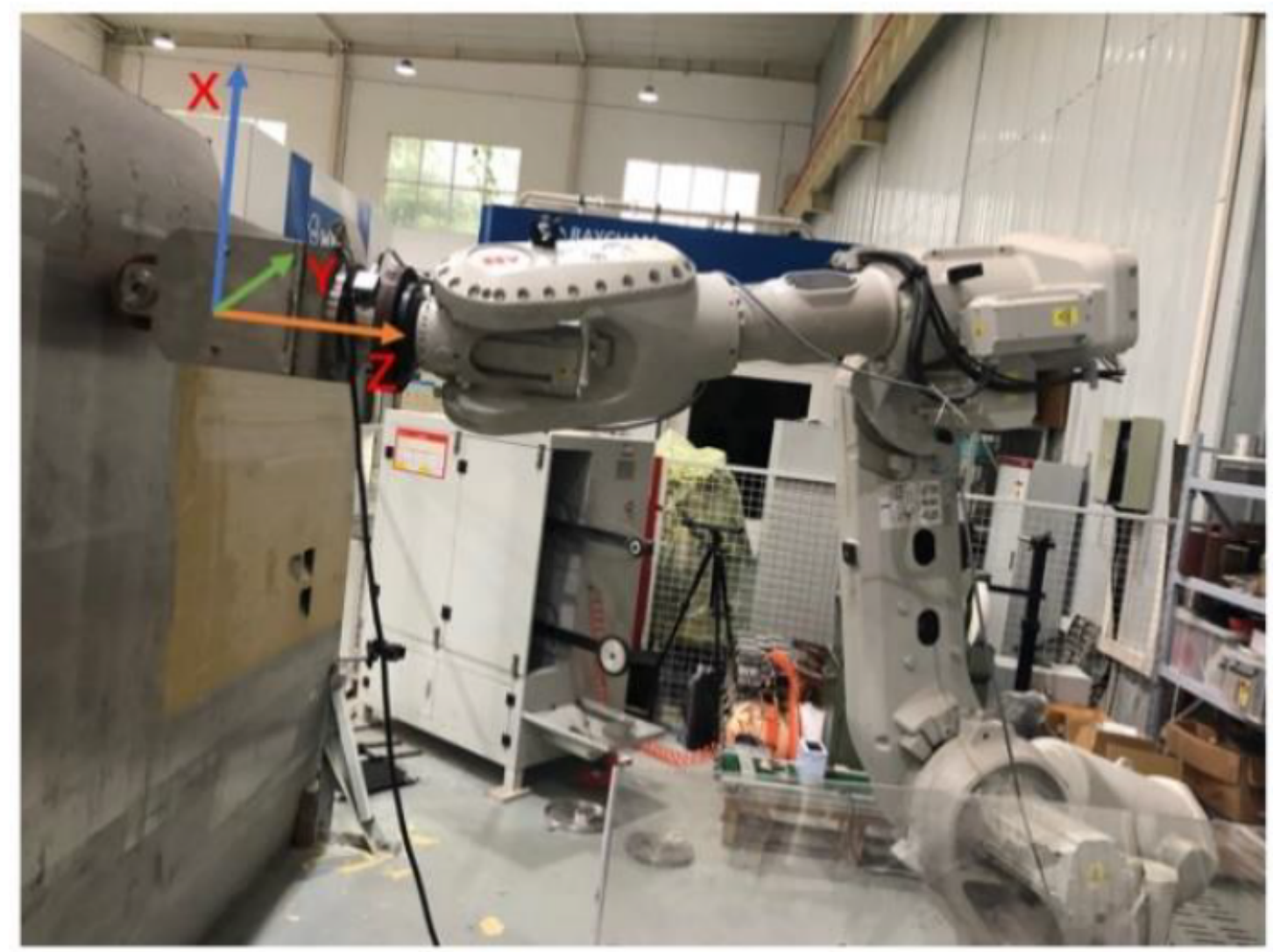

Figure 10

Experimental platform of robotic grinding and brushing of high-speed rail body.

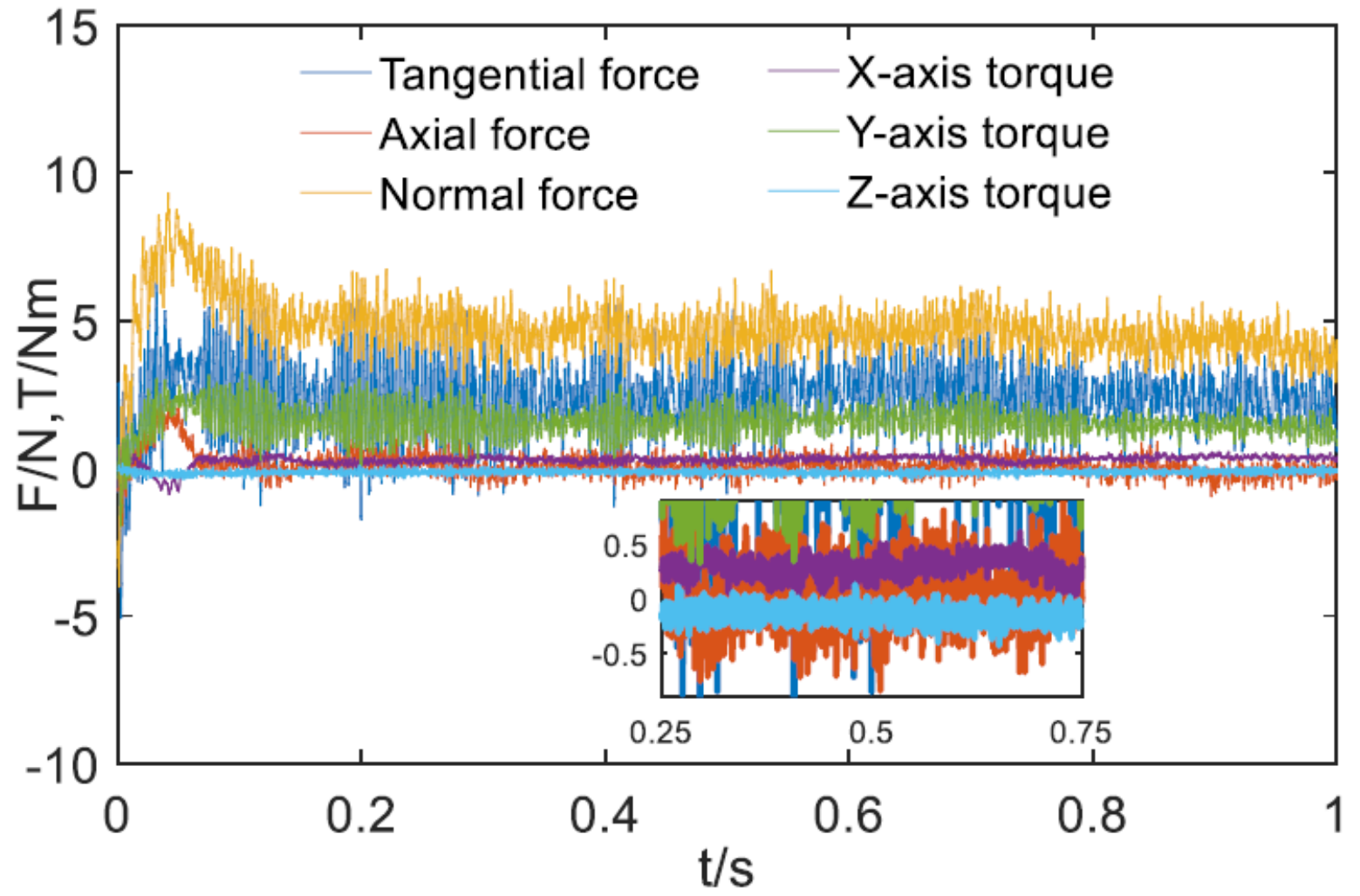




\section{Figure 11}

Force and torque signals monitored by the ATI force sensor.

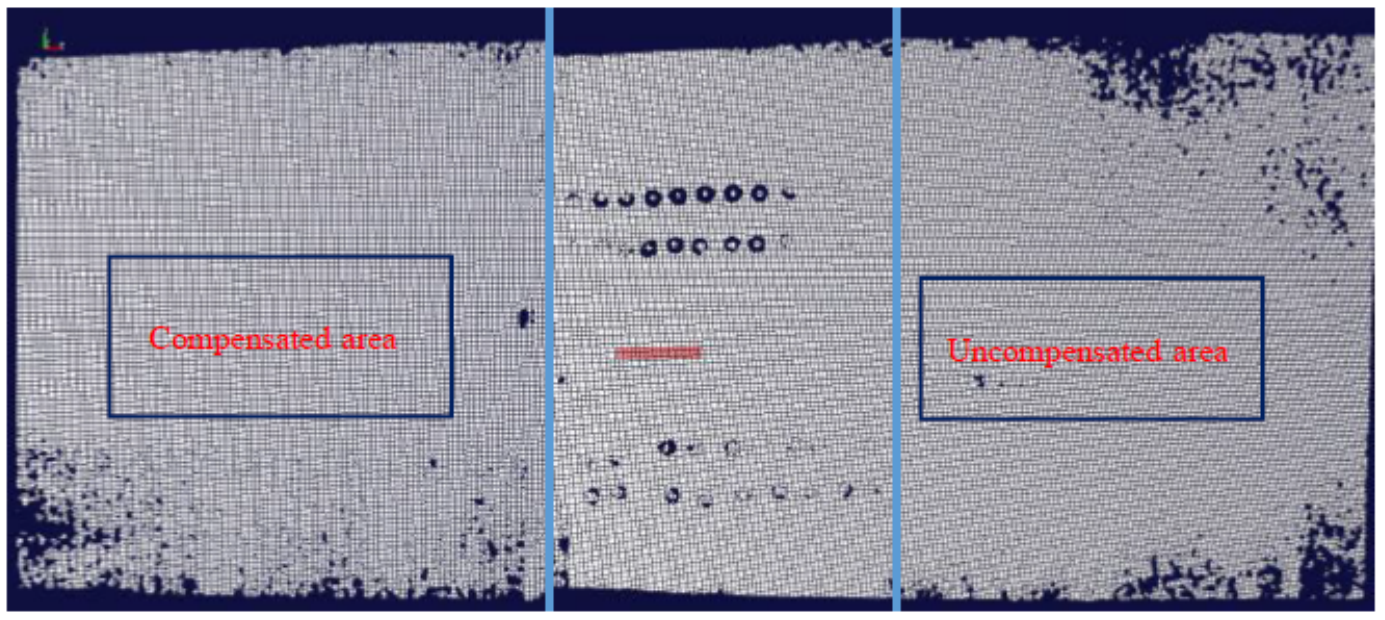

\section{Figure 12}

The selected areas of high-speed rail body to be ground and brushed. 

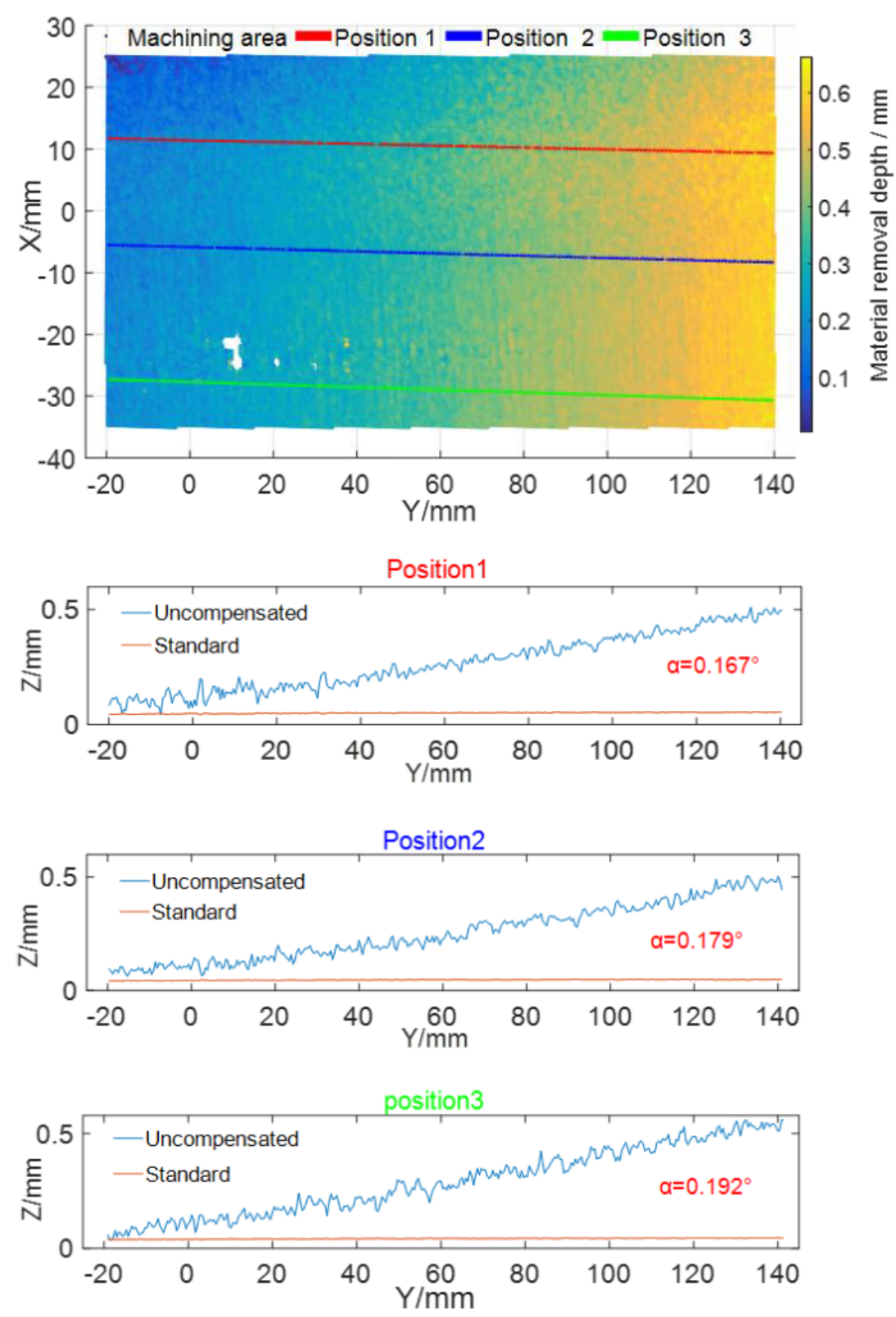

\section{Figure 13}

Depth of material removal in the uncompensated areas after grinding and brushing. 

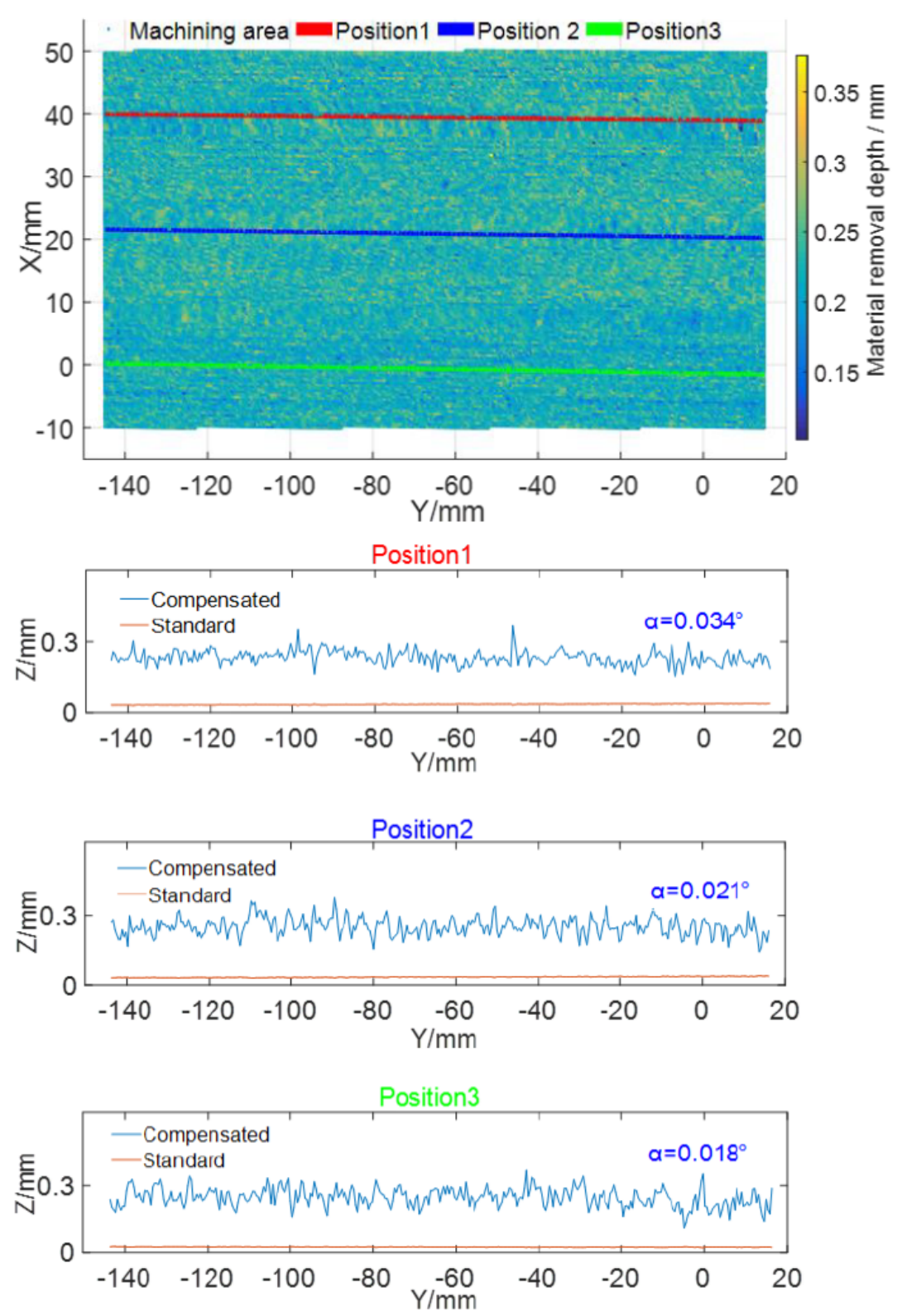

\section{Figure 14}

Depth of material removal in the compensated areas after grinding and brushing. 